\title{
Pressure-assisted cyclic washing of heavy-metal-contaminated sediments
}

\author{
C. E. Lin $\cdot$ P. K. A. Hong $\cdot$ H. Y. Chiu • \\ R. Y. Surampalli · C. T. Lin · C. M. Kao
}

Received: 16 August 2012/Revised: 8 March 2013/Accepted: 23 April 2013/Published online: 17 May 2013

(C) Islamic Azad University (IAU) 2013

\begin{abstract}
Remediation of heavy-metal-contaminated sediment is often hampered by the availability of heavy metals to the added chemical agents because the heavy metals are often shielded by the sediment matrix. Effective heavy-metal extraction technique becomes an important factor in enhancing the treatment efficiency. A novel extraction/washing technique utilizing chelating agent and elevated pressure in consecutive cycles of compression and decompression has been developed for heavy-metal-contaminated sediment washing in the presence of chelating agent. In this study, the optimal operational conditions of pressure-assisted cyclic washing of $\mathrm{Cu}$-contaminated sediments (initial $\mathrm{Cu}$ concentration $=23.177 \mathrm{mg} / \mathrm{kg}$ ) were determined in a laboratory-scale system. The control factors included applied pressure level, washing time, applied chelant [ethylenediamine-tertraacetic (EDTA)] concentration $(0.01-0.5 \mathrm{M})$, pressure times, and application of consecutive batches washing. Results from the bench-scale study showed that up to $70 \%$ of $\mathrm{Cu}$ can be removed from the sediments when $10 \mathrm{~atm}$ of pressure was applied for
\end{abstract}

C. E. Lin · H. Y. Chiu · C. M. Kao $(\bowtie)$

Institute of Environmental Engineering, National Sun Yat-Sen

University, Kaohsiung 804, Taiwan

e-mail: jkao@mail.nsysu.edu.tw

P. K. A. Hong

Department of Civil and Environmental Engineering,

University of Utah, Salt Lake City, UT, USA

R. Y. Surampalli

Department of Civil Engineering, University of Nebraska, Lincoln, NE, USA

C. T. Lin

Department of Marine Environmental Engineering,

National Kaohsiung Marine University, Kaohsiung, Taiwan washing. The efficiency dropped to $55 \%$ when the pressure dropped to $6 \mathrm{~atm}$. Under the same operational conditions, the optimal cyclic washing time was $60 \mathrm{~min}$. Results from the particle size analyses indicate that the mean particle size dropped from 100 to $50 \mu \mathrm{m}$ after the pressure-assisted cyclic washing. Thus, cyclic pressure caused the fracture of sediment aggregates resulting in the exposure of $\mathrm{Cu}$ to chelating agents. With the assistance of pressure cyclic system, the total washing time and the amount of added chemical agent used can be significantly reduced.

Keywords Chelating agent - Heavy metal · Pressureassisted cyclic washing - Sediment contamination

\section{Introduction}

Heavy metals originating from anthropogenic activities are frequently detected in sediments and water columns of rivers or lakes, which have caused a considerable number of sediment-contaminated sites in the world (Theofanis et al. 2001; Arribere et al. 2002; Susana et al. 2005; Yang et al. 2009; Gao et al. 2012). In the aquatic systems, removal of the heavy metals from the water to sediments usually occurs through particle settlement while some of these pollutants can be mobilized by getting accumulated into the biota from the sediment sink (Singh et al. 2005; Khaled et al. 2006; Demirak et al. 2006; Peng et al. 2009; Lin et al. 2011). More than $90 \%$ of the anthropogenic metals are bound to particulate matters and deposited on the beds of water bodies, synchronously adsorbed on the debris from the weathered mother rocks and soils in the catchment (Akcay et al. 2003; Demirak et al. 2006; Ghrefat and Yusuf 2006; Amin et al. 2009). Due to the variation in 
weathering, erosion, transport conditions, and aquatic productivity, the accumulated sediments have different characteristics (e.g., grain size, mineral, and organic matter content), which can create anomalously high heavy-metal concentration as well as anthropogenic contamination (Liaghati et al. 2003; Chen et al. 2004; Reimann and de Caritat 2005; Harikumar and Nasir 2010; Bhakta et al. 2012).

Contaminants of heavy metals are not necessarily fixed permanently by the sediments, and they may be released to the water column by various processes of remobilization under changing environmental conditions (Uta and Jens 2006; Jayawardana et al. 2012). The fixation percentage of heavy metals on sediment matrix may range from $100 \%$ to none when $\mathrm{pH}$ value is a few units lower (Gundersen and Steinnes 2003; Chiu et al. 2011). Results from a field study (Theofanis et al. 2001) show that approximately 18 ton of $\mathrm{Zn}$ can be released from sediments of the Mulde reservoir (located in Saxony, Germany) into water only due to the fact that sediment being disturbed and oxidized in flooding, which led to a significant increase in $\mathrm{Zn}$ concentration in water (Theofanis et al. 2001). Thus, sediments play an important role in determining pollution patterns of aquatic systems (Casas et al. 2003); they act as both carriers and sinks for contaminants, reflecting the history of pollution (Chen et al. 2012a) and providing a record of catchment inputs into aquatic ecosystems (Mwamburi 2003). However, unlike most organic compounds that can biodegrade or decay naturally with time, heavy metals are robust, and thus, they remain a potential threat to the environment and human health for a long period of time (Chen et al. 2012b).

For the slightly polluted sediments, in situ remediation techniques are usually applied. However, effects of in situ remediation are not significant for those heavily polluted sediments because the uncontrolled environmental conditions make their remediation efficiency ignorable. Under such conditions, ex situ sediment remediation becomes the first choice because the sediment remediation process can be performed under controlled conditions (Catherine et al. 2001; Gustavon et al. 2008; Polettini et al. 2009; Tsai et al. 2009; Liang and Huang 2012). Most ex situ remediation technologies for soil or mineral ores can be used for dredged sediments. However, due to higher workload and different environmental characteristics in sediments, some technologies have higher costs and more complex when used in sediment remediation. In general, the feasible techniques that aim to remove heavy metals from contaminated sediments include electrochemical remediation, flotation, ultrasonic extraction, sediment washing, and immobilization (Peng et al. 2009). Among these ex situ remediation methods, sediment washing is a commonly used technique to enhance heavy-metal removal from sediments. Sediment washing is a relatively simple and useful ex situ remediation technology. During the sediment washing process, water is used for sediment rinsing and washing, and heavy metals can be transferred from the dredged sediments to wash solution (Wasay et al. 2001; Palma and Mecozzi 2007). To enhance the performance of sediment washing, various additives can be employed. The commonly applied additives include acids (e.g., $\mathrm{H}_{2} \mathrm{SO}_{4}$, $\mathrm{HNO}_{3}$ ), chelating agents [e.g., ethylenediaminetetraacetic acid (EDTA), diethylene triamine pentaacetic acid (DTPA), Ethylenediamine- $N, N^{\prime}$-disuccinic acid (EDDS)], surfactants (e.g., rhamnolipid).

Among these additives, acids and chelating agents are the most commonly used extractive reagents for heavymetal decontamination. Acid washing leads to decreased soil productivity and adverse changes in the chemical and physical structures of soils due to mineral dissolution (Reed et al. 1996; Singh et al. 2005; Hong et al. 2008). The most extensively studied chelating agents for soil washing have been reported to appreciably increase the dissolution and mobilization of cationic heavy metals (Lim et al. 2004; Tandy et al. 2004) and have low aquatic toxicity and no bioaccumulation in living organisms through the food chain (ECB 2004). Thus, they can function as one of promising washing agents for the remediation of metalcontaminated sites.

The possible disadvantages of using chelating agents as compared to acids include the following: (1) chelating agents might pose a potential environmental hazard if they remain in the treated media, and (2) chelating agents are relatively expensive chemicals compared to acids. However, if the applied chelating agents can be recovered and recycled and high treatment efficiency of heavy metals can be obtained, the adverse impact for using chelating agents for sediment washing can be reduced (Hong et al. 1999; Juang and Wang 2000; Barona et al. 2001; Voglar and Lestan 2010). Therefore, the chelating agent-enhanced sediment washing technique will offer technical as well as economic merits. The advantages of using chelating agents in sediment washing are higher efficiency of metal extraction, higher thermodynamic stabilities of the metal complexes formed, higher solubilities of metal complexes, and lower adsorption of the chelating agents and their metal complexes on sediments (Fischer et al. 1998; Zhang and Lo 2006). In comparison with other chelating agents, EDTA has a high level of complex capacity with respect to heavy metals (Abumaizar and Smith 1999; Martinez 2000; Xia et al. 2009). Although EDTA is effective on removing heavy metals from contaminated soils, the treatment agents must come into contact with the target contaminants. However, access to the target contaminants is often hampered by the soil matrix that physically shields the contaminants from exposure to the treatment agent in solution, resulting in poor or incomplete removal of the target 
contaminants (Cassidy and Irvine 1998; Xia et al. 2009). Mechanical agitation has been applied to allow effective contact of contaminants with the chemical agents. However, in most cases, mechanical agitation only enhances the slurry phase mixing through macropore agitation. The agitation power is not effective enough to desorb the heavy metals from the micropores of sediment matrix (Elliott and Shastri 1999; Zou et al. 2009; Shiue et al. 2012).

To overcome this limitation and increase the contact between chelating agents and heavy metals, a unique cyclic washing concept has been developed that utilizes chelants and mildly elevated pressure in consecutive cycles of compression and decompression to desorb contaminants from soil particles. Application of high pressure and high temperature (e.g., $1,500 \mathrm{psi},>100{ }^{\circ} \mathrm{C}$ ) for soil contaminant extraction have been reported (Moreda-Pineiro et al. 2006; Wanekaya et al. 2002). Wanekaya et al. (2002) described a digestion technique to remediate heavy-metal-contaminated solid matrices. This technique was based on the use of solvents at high pressure (from 500 to 3,000 psi) and/or high temperature $\left(200{ }^{\circ} \mathrm{C}\right)$ without reaching the critical point. Moreda-Pineiro et al. (2006) applied strong acetic acid $(8.0 \mathrm{M})$ at high pressure and temperature $(1,500 \mathrm{psi}$, $100{ }^{\circ} \mathrm{C}$ ) to enhance the metal extraction from marine sediments and soils. However, the use of relatively low pressure (e.g., $150 \mathrm{psi}$ ) at room temperature to enhance heavy-metal washing from sediments has not been reported.

In this study, a laboratory-scale pressure-assisted sediment cyclic washing device was developed to evaluate the effectiveness of applying the pressure cyclic system on heavy-metal washing from sediments. Because $\mathrm{Cu}$ is the most commonly found heavy metal in the river sediments in Taiwan, it was used as the target contaminant in this study. Copper-contaminated sediments collected from a polluted river were used in the tests. The objectives of this study were to (1) evaluate the effectiveness of using EDTA on heavy-metal $(\mathrm{Cu})$ extraction from river sediments (2) evaluate the effectiveness of pressure-assisted compression and decompression cyclic system to desorb $\mathrm{Cu}$ from sediment matrix using EDTA, and (3) determine the optimal operational conditions of the pressure-assisted cyclic washing system for $\mathrm{Cu}$-contaminated sediment remediation. The control factors included applied pressure level, washing time, applied chelant concentration, pressure times, and application of consecutive washing with fresh solutions. This research was carried out in Kaohsiung City, Taiwan from August 2009 to July 2011. All sediment samples were collected from the Salt-water River in Kaohsiung City, and the laboratory-scale pressure-assisted sediment cyclic washing experiment was conducted at the Institute of Environmental Engineering, National Sun YatSen University, Kaohsiung City.

\section{Materials and methods}

In this study, sediment samples were collected from the Salt-water River in Kaohsiung City, Taiwan. Particle size distribution was determined by the sieve analysis method for the particles with sizes higher than $1 \mathrm{~mm}$. The particle analyzer (Coulter ${ }^{\circledR}$ LS 100, RSG, Inc., Sylacauga, Alabama, USA) was used to analyze the particle distribution for the particles with sizes smaller than $1 \mathrm{~mm}$ (NIEA 2003). Sediment $\mathrm{pH}$ and ORP values were determined using slurry phase analytical method (weight ratio for sediment to water $=1$ to 1 ) (NIEA 2005). A pH meter (Mettler Toledo, USA) and an ORP meter (Mettler Toledo, USA) were applied for $\mathrm{pH}$ and ORP analyses, respectively. $\mathrm{Cu}$ concentration in the extract was analyzed with the use of standards prepared from $\mathrm{Cu}\left(\mathrm{NO}_{3}\right)_{2}(>99.0 \%$, Merck, USA) by flame atomic absorption spectrometry (PerkineElmer Model 280, USA) per NIEA method S321.63B. EDTA (concentrations $=0.01-0.5 \mathrm{M}$ ) was used to extract $\mathrm{Cu}$ from sediments $(20 \mathrm{~g}$ sediment in $1 \mathrm{~L}$ of EDTA solution), corresponding to EDTA/Cu mole ratios of 1.5-65. The initial sediment $\mathrm{pH}$ was adjusted to neutral $(\mathrm{pH}=7)$ using $\mathrm{HNO}_{3}$ or $\mathrm{NaOH}$ solution $(5 \mathrm{M})$. All reagents used in this study were analytical grades.

The pressure-assisted cyclic washing device (reactor) used in this bench-scale study is shown in Fig. 1. The reactor was a stainless steel vessel with a wall thickness of $1 \mathrm{~cm}$. It had an internal diameter of $30 \mathrm{~cm}$ and a working volume of $3.5 \mathrm{~L}$. The top of the reactor contained a gas vent, a pressure gauge, and a gas inflow line. A compressed nitrogen gas tank (industrial grade $99.5 \%$ ) was used to provide pressurization to the reactor. The mechanical coupled stirrer provided agitation and suspension of the slurry as necessary. At the start of extraction, the reactor was loaded with sediments and water at a desired solid-toliquid ratio (1:50 w/w) along with EDTA at the desired concentration. A pressure cycle began with the compression stage when the regulator of the compressed nitrogen gas tank was opened to introduce gas into the closed reactor chamber through the electronic valves and through a gas diffuser plate located at the bottom inside the reactor. Nitrogen gas passed through the sediment slurry and pressurized the headspace of the reactor to reach a designated pressure (e.g., $10 \mathrm{~atm}$ or $150 \mathrm{psi}$ ); once the designated pressure was reached, the headspace was released through gas vent by opening the electronic valves at the reactor top. All of the electronic valves were controlled by programmable logic controller (PLC). The pressure cycles could be repeated as many times as predetermined. The time for compression to reach $10 \mathrm{~atm}(150 \mathrm{psi})$ depended on the headspace volume (e.g., $30 \mathrm{~s}$ for $2,500 \mathrm{~mL}$ of headspace or $15 \mathrm{~s}$ for $1,500 \mathrm{~mL}$ of headspace) and other factors such as gas flow rate; the time for decompression 
Fig. 1 Schematic diagram of the reactor

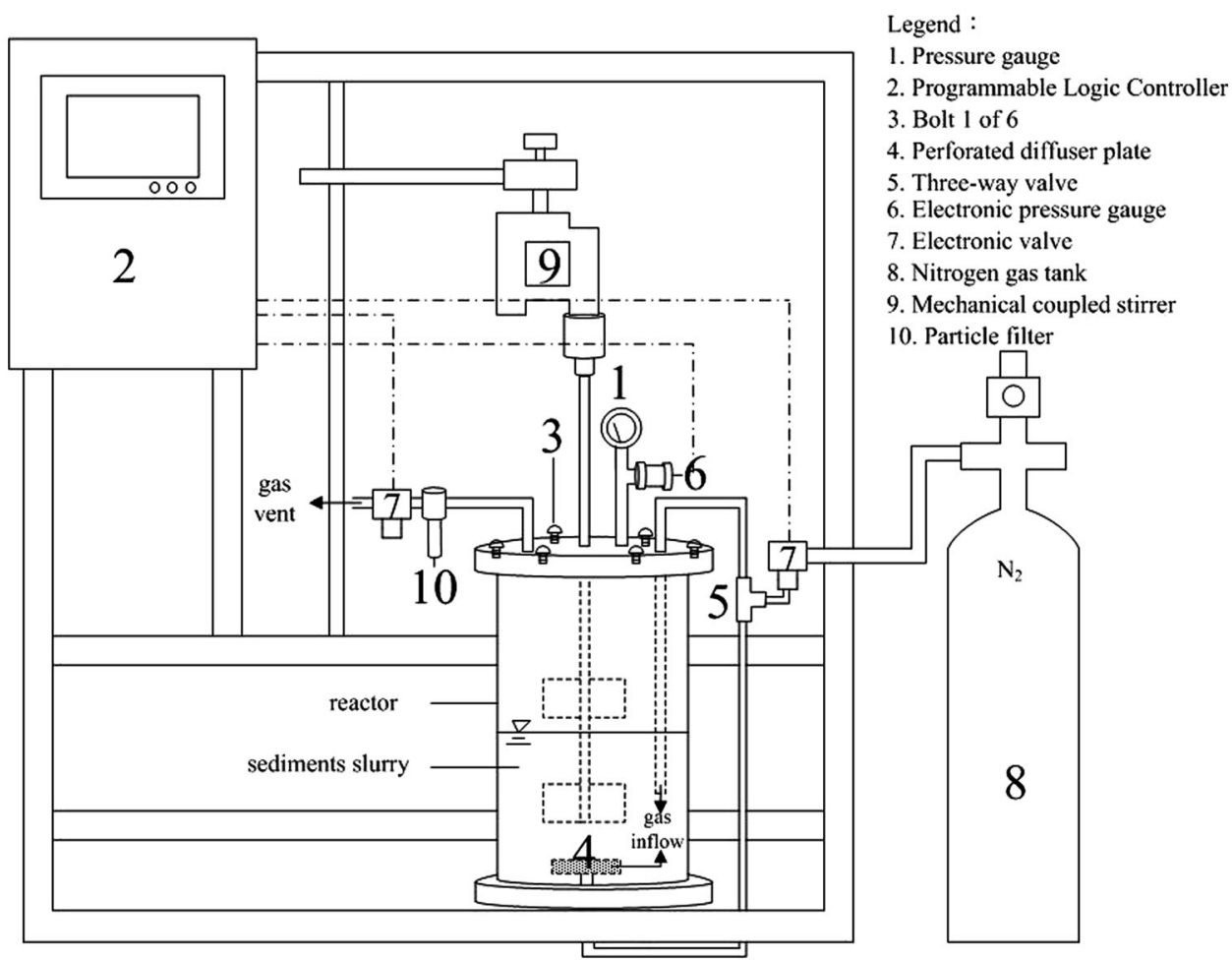

varied with gas venting rate, but typically in seconds. After the predetermined contact time and pressure cycles, the cyclic washing was stopped and the sediment and liquid contents were separated by vacuum filtration. The sediments after experiment were analyzed for $\mathrm{Cu}$ content. Each experiment was performed in triplicates. Mean and standard deviations of the triplicates were calculated.

\section{Results and discussion}

The chemical and physical properties of the sediments are shown in Table 1 . The sediment analytical results reveal that the total concentrations of $\mathrm{Cu}, \mathrm{Zn}$, and $\mathrm{Ni}$ in sediments of Salt-water River exceeded the tentative National Sediment Standards determined by Taiwan Environmental Protection Administration (TEAP) $(\mathrm{Cu} \leq 400 \mathrm{mg} / \mathrm{kg}$, $\mathrm{Zn} \leq 2,000 \mathrm{mg} / \mathrm{kg}, \quad \mathrm{Ni} \leq 200 \mathrm{mg} / \mathrm{kg}$ ) (TEPA 2012). Results show that $\mathrm{Cu}$ had the highest concentration compared to other heavy metals in the sediments. Therefore, $\mathrm{Cu}$ was selected as the target metal to evaluate the effectiveness of pressure-assisted cyclic washing on heavy-metal removal from sediments using EDTA as the chelating agent. Because the sediments contained high concentrations of heavy metals, biological treatment or phytoremediation might not be appropriate remedial alternatives. Particle size distribution analysis indicate that the sediments contained approximately $22 \%$ of sand-size particles $(2-0.05 \mathrm{~mm}), 70 \%$ of silt-size particles $(0.002-0.05 \mathrm{~mm})$, and $8 \%$ of clay $(<0.002 \mathrm{~mm})$. This indicates that the sediments were mainly silty loam.

To test the theoretical postulation of sediments particle fracture under repeated compression and decompression cycles, sediment particle size distributions were measured prior to treatment, after 30 and $100 \mathrm{~min}$ of pressurization to $6 \mathrm{~atm}$ (90 psi), and after 30, 60, 90, and $120 \mathrm{~min}$ of pressurization to $10 \mathrm{~atm}$ (150 psi). Figure 2 shows the various size fractions of the sediment particles analyzed by sieves and LS 100 particle analyzer for sediments before treatment, treatment by $6 \mathrm{~atm}$ for 30 and $100 \mathrm{~min}$ of pressure cycles, and treatment by $10 \mathrm{~atm}$ for 30-120 min of pressure cycles. Results show that silt $(70 \%)$ was the dominant particle size followed by sand $(22 \%)$ and clay $(8 \%)$ prior the pressure treatment. In the treatment with the pressure of $6 \mathrm{~atm}$ and cyclic time of $30 \mathrm{~min}$, the percentages of silt, sand, and clay changed to 79,12 , and $9 \%$, respectively. Results show that significant variations ( $9 \%$ increase in silt component and $10 \%$ decrease in sand component) in the percentages of three components were observed before and after the treatment. When the cyclic time increased to $100 \mathrm{~min}$ and the pressure remained at $6 \mathrm{~atm}$, the percentages of silt, sand, and clay changed to 80,12 , and $8 \%$, respectively. Although the sediment type changed from silty loam to silt with longer treatment time (100 min), only slight change of the percentage change was observed. Results also show that when the pressure increased to $10 \mathrm{~atm}$ and the cyclic time was $60 \mathrm{~min}$, the percentages of silt, sand, and clay changed to 86,2 , and $12 \%$, 
Table 1 Characteristics of sediments

\begin{tabular}{ll}
\hline Item & Value \\
\hline $\mathrm{pH}$ & 7.34 \\
Water content $(\%)$ & 23 \\
Organic matter $(\%)$ & 24.58 \\
ORP $(\mathrm{mV})$ & -193 \\
$\mathrm{Zn}(\mathrm{mg} / \mathrm{kg})$ & 4,830 \\
$\mathrm{~Pb}(\mathrm{mg} / \mathrm{kg})$ & 159 \\
$\mathrm{Ni}(\mathrm{mg} / \mathrm{kg})$ & 211 \\
$\mathrm{Cu}(\mathrm{mg} / \mathrm{kg})$ & 23,177 \\
$\mathrm{Cr}(\mathrm{mg} / \mathrm{kg})$ & 134 \\
$\mathrm{Cd}(\mathrm{mg} / \mathrm{kg})$ & $\leq 0.1$ \\
$\mathrm{Sand}(\%)(2-0.05 \mathrm{~mm})$ & 23.39 \\
$\mathrm{Silt}(\%)(0.05-0.002 \mathrm{~mm})$ & 70.56 \\
Clay $(\%)(<0.002 \mathrm{~mm})$ & 6.05 \\
\hline
\end{tabular}

respectively. When the cyclic time increased to $120 \mathrm{~min}$ and the pressure remained at $10 \mathrm{~atm}$, the percentages of silt, sand, and clay changed to 86,3 , and $11 \%$, respectively. Results indicate that higher pressure (10 atm) caused the significant change (sediment type changed from silty loam to silt) of the sediment formation. The formation change was not significant when the cyclic time was extended from 60 to $120 \mathrm{~min}$ (only $1 \%$ increase in sand component and $1 \%$ decrease in clay component). However, when the cyclic time dropped from 60 to $30 \mathrm{~min}$, the percentage of silt also dropped from 86 to $79 \%$, which caused the sediment type changed from silt to silty loam. Thus, both pressure and cyclic time have impact on the change of the sediment formation, which caused the fracturing of sediment particles.

The decreased particle sizes suggest significant breaking of the soil particles into the smaller ones $(<0.05 \mathrm{~mm})$ by the pressure cycles. Because the coarse-medium fraction of the sediment was of aggregates of clay-sized particles rather than typical quartz sand particles; the aggregates were disrupted by pressure cycles into constituent finegrained particles. The accumulation of hydrophobic contaminants in soil aggregates was discussed by Cassidy and Irvine (1998). Liu and Cheng (2007) reported that heavy metals were mainly adsorbed onto finer particles (e.g., silt, clay), and thus, less heavy metals can be adsorbed onto sand particles. Liu and Cheng (2007) analyzed three different soils and found that sand particles contained relatively low heavy-metal concentrations. Results from this test also show that the decreased soil particle sizes were caused by the exposure to compression and decompression cycles. However, the silt fraction increased with pressure cycle time and stabilized beyond $60 \mathrm{~min}$ (10 atm). It indicates that under the pressure of $10 \mathrm{~atm}$, the required time to cause the breakdown of sediments was $60 \mathrm{~min}$. In comparison with other study (Hong et al. 2008), the time (number of cycles) required to breakdown the sediment matrix was more than the time required for breaking down soil formation. This indicates that although the pressureassisted cyclic washing is able to cause the rupture of the sediment matrix, it is more rigid and the binding strength between the particles is stronger than soil matrix. Therefore, longer reaction time might be required when the pressure-assisted cyclic system is applied for breaking down the sediment. The fracturing of sediment particles is expected to increase exposure of contaminants heretofore sheltered in the sediment matrix to the bulk liquid environment. Thus, the exposure of $\mathrm{Cu}$ in sediments to EDTA (chelating agent) in the aqueous phase would lead to enhanced chelation and therefore, effective contaminant removal. The effectiveness of pressure cycle-assisted washing is subject to varied operation parameters to be presented, and the benefits of deploying the pressure cycles will be delineated.

Figure 3 shows amounts of extracted $\mathrm{Cu}$ under the operational conditions of EDTA concentrations and pressures employed at the compression stage. Results from the cyclic washing experiment show that the amount of
Fig. 2 Sediment particle size distributions before treatment, after 30 and 100 min pressure cycle at $6 \mathrm{~atm}$, and after 30-120 min pressure cycles at $10 \mathrm{~atm}$, respectively

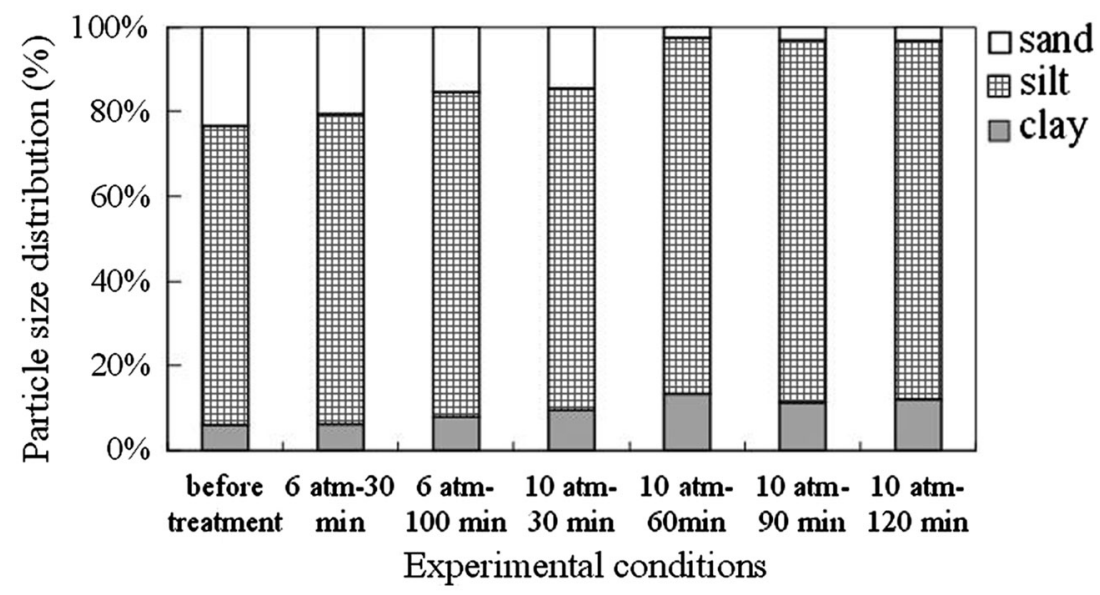




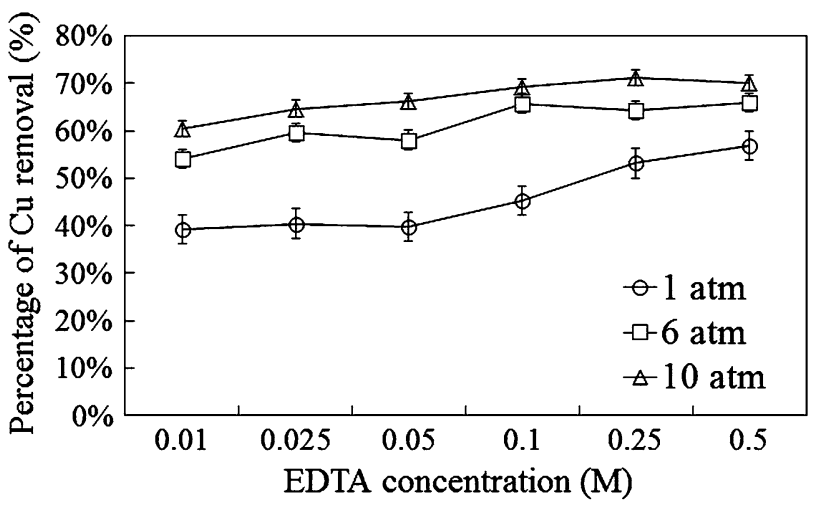

Fig. 3 Extraction of $\mathrm{Cu}$ from sediments using different pressures and EDTA concentration (other conditions: sediment slurry, $20 \mathrm{~g} /$ $1,000 \mathrm{~mL}$ water; experiment time: $2 \mathrm{~h}$ )

extracted metal increased with increased pressure and EDTA concentration. This reveals that both pressure and EDTA played important roles in the efficiency of $\mathrm{Cu}$ removal. When pressure was $1 \mathrm{~atm}$ (no pressure test), increase in EDTA concentration from 0.01 to $0.5 \mathrm{M}$ caused increase in $\mathrm{Cu}$ removal efficiency from 40 to $57 \%$, respectively. When pressure was $10 \mathrm{~atm}$, increase in EDTA concentration from 0.01 to $0.5 \mathrm{M}$ caused increase in $\mathrm{Cu}$ removal efficiency from 60 to $70 \%$, respectively. Results indicate that pressure-assisted cyclic washing had significant enhancement in $\mathrm{Cu}$ removal efficiency. This could be due to the fact that the increased exposure of $\mathrm{Cu}$ to the liquid phase in the fractured sediments, and thus, $\mathrm{Cu}$ concentration in sediments would be reduced. Moreover, the application of the pressure cyclic system would also minimize the amount of EDTA addition. Therefore, the chelating-agent cost can be reduced.

Table 2 shows the calculated molar ratios between added EDTA and heavy metals (sum of $\mathrm{Zn}, \mathrm{Pb}, \mathrm{Ni}, \mathrm{Cu}$, and $\mathrm{Cr}$ ) in each test. The lowest and highest molar ratios for EDTA to heavy metals were 1.1:1 and 56.4:1, respectively. Results from Fig. 3 indicate that the excess dosage would ensure that higher EDTA concentrations $(0.1 \mathrm{M}$ for 6 and 10 -atm treatment and $0.25 \mathrm{M}$ for 1 -atm treatment) would not cause significant increase in $\mathrm{Cu}$ removal. This might be due to the fact that some molecules of the EDTA might adsorb onto sediment matrix and might also form complexes with other cations (e.g., $\mathrm{Ca}, \mathrm{Mg}, \mathrm{Fe}, \mathrm{Al}$ ) originally present in the sediments. Even if more $\mathrm{Cu}$ was extracted with increased dosage of chelating agent, some of the heavy-metal complexes formed could be readsorbed by sediment solids. Therefore, extra EDTA addition (molar ratio of 11.3:1 for 10-atm treatment and molar ratio of 28.2:1 for 6 and 10-atm treatments) was not bound to the increase in $\mathrm{Cu}$ removal because of the complex nature of sediment matrix. Thus, preliminary feasibility is a necessity to determine the optimal dosage of chelating agent.
Table 2 Calculated molar ratios between EDTA and heavy metals $(\mathrm{Zn}+\mathrm{Pb}+\mathrm{Ni}+\mathrm{Cu}+\mathrm{Cr})$

\begin{tabular}{lll}
\hline $\begin{array}{l}\text { EDTA concentration } \\
(\mathrm{M})\end{array}$ & $\begin{array}{l}\text { L/S (mg/ } \\
\mathrm{g})\end{array}$ & $\begin{array}{l}\text { Molar ratio (EDTA to heavy } \\
\text { metals) }\end{array}$ \\
\hline 0.01 & 50 & $1.1: 1$ \\
0.025 & 50 & $2.8: 1$ \\
0.05 & 50 & $5.6: 1$ \\
0.1 & 50 & $11.3: 1$ \\
0.25 & 50 & $28.2: 1$ \\
0.5 & 50 & $56.4: 1$ \\
\hline
\end{tabular}

$L / S$ liquid to soil ratio

Apparently, if taking into consideration the chemical cost, appropriate chelating-agent dosage should be favorable over a high dosage in sediments extraction of heavy-metalcontaminated sediments.

Figure 4 presents the benefits of consecutive extractions at optimal EDTA concentration $(0.025 \mathrm{M})$. For each cyclic washing, $1 \mathrm{~L}$ of EDTA solution $(0.025 \mathrm{M})$ was applied. The results show that up to $78 \%$ of $\mathrm{Cu}$ can be removed from $50 \mathrm{~g}$ of sediments via three consecutive washings. However, only $69 \%$ of $\mathrm{Cu}$ could be washed out from $50 \mathrm{~g}$ of sediments by a single cyclic washing with $1 \mathrm{~L}$ of $0.1 \mathrm{M}$ EDTA solution (Fig. 3). Thus, consecutive cyclic washing shows significant benefits over a single washing in increased $\mathrm{Cu}$ extraction and reduced EDTA concentration. From an engineering point of view, consecutive cyclic washing is an appropriate measure for practical sediment remediation project.

Figure 5 illustrates the percentages of $\mathrm{Cu}$ removed as a function of washing time with $0.1 \mathrm{M}$ of EDTA. Results show that rapid $\mathrm{Cu}$ removal was observed during the early operational period (100 min for treatment by pressure of $10 \mathrm{~atm}$ and $220 \mathrm{~min}$ for treatment by pressure of $1 \mathrm{~atm}$ ) followed by a slight and insignificant $\mathrm{Cu}$ removal. Bermond and Ghestem (2001) reported a rapid initial release of $\mathrm{Cu}$ from the contaminated soil into the EDTA-extracting solution. Lee (2003) also found that short extraction time $(<60 \mathrm{~min})$ was sufficient to remove a significant portion of extractable heavy metals from the contaminated soils (Lee 2003). Results reveal that approximately $60 \%$ of $\mathrm{Cu}$ removal was accomplished with only mechanical agitation $(250 \mathrm{rpm})$ without pressuring (1 atm) after $220 \mathrm{~min}$ of operation. The $\mathrm{Cu}$ removal efficiency went up to $70 \%$ with pressureassisted washing using pressure of $10 \mathrm{~atm}$ after $100 \mathrm{~min}$ of operation. Extending the extraction time beyond the break point did not further enhance the $\mathrm{Cu}$ removal efficiency. Results reveal that longer washing time was required to reach the break point, and less removal efficiency was obtained if pressure was not provided. Therefore, pressure-assisted cyclic washing plays a key role in improving the effectiveness of using EDTA on $\mathrm{Cu}$ extraction from sediments. 


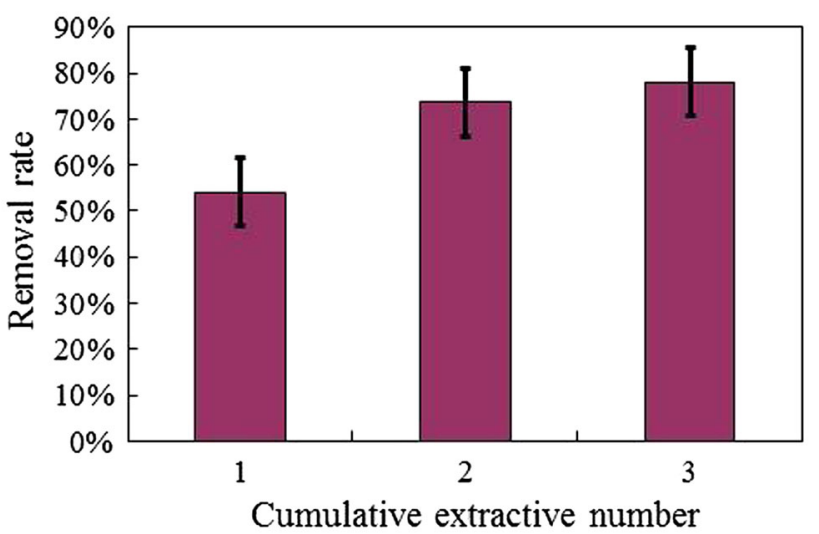

Fig. 4 Cumulative extraction of $\mathrm{Cu}$ from sediments during consecutive batches of extraction using fresh EDTA solution at different concentrations (conditions: pressure, $10 \mathrm{~atm}$ ); time of cycles, $60 \mathrm{~min}$ each batch; soil slurry, $50 \mathrm{~g} / 1,000 \mathrm{~mL}$ )

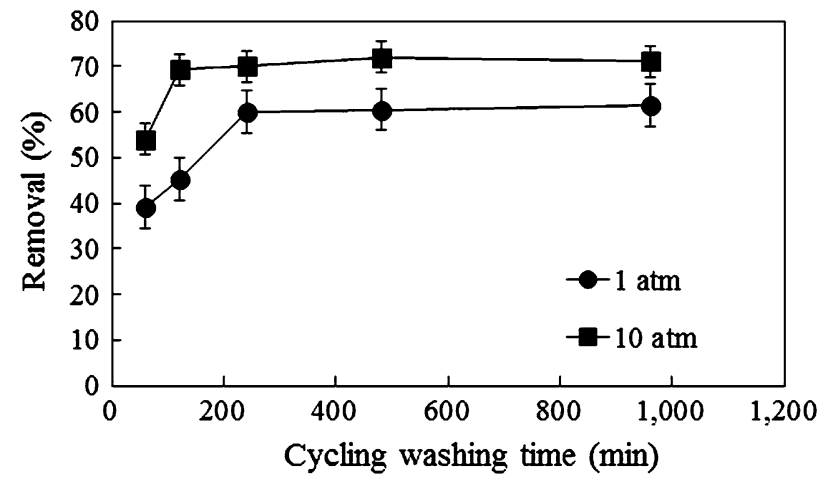

Fig. 5 Percentage of heavy metals extracted by EDTA at a pH of 7.0 as a function of extraction time (other conditions: sediments slurry, $20 \mathrm{~g} / 1,000 \mathrm{~mL}$ water; EDTA: $0.1 \mathrm{M}$ )

In this study, the main concept was to increase the contact frequency between contaminants (e.g., $\mathrm{Cu}$ ) within the sediment structures and chelating agents (e.g., EDTA), and thus, the contaminant removal rate could be enhanced due to the increased efficiency and effectiveness of the reaction. The increased exposure of contaminants was made possible by fracturing the sediment particles through successive cycles of compression and decompression with an inactive gas (e.g., $\mathrm{N}_{2}$, air) into a liquid carrying the contaminated sediments in the presence of a chelating agent. Figure 6 presents the operational process and principle of the designed system. The sediment aggregates included sand, silt, clay, and organic matter (Fig. 6a). Under pressure, the liquid carries highly pressurized dissolved gas into pores (Fig. 6b) and the chelating agent from soluble complexes with contaminants. During the decompression process, gas formation occurs within the sediment pores, expelling extract-containing contaminant (e.g., $\mathrm{Cu}$

\section{(a)}

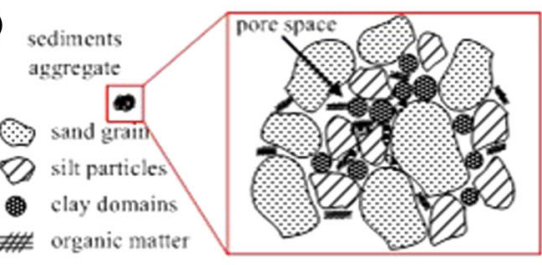

fopper

马ुEDTA

(b) liquid with

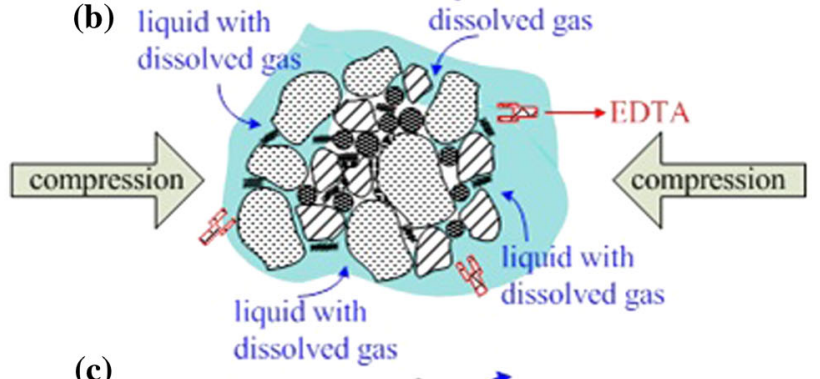

(c)
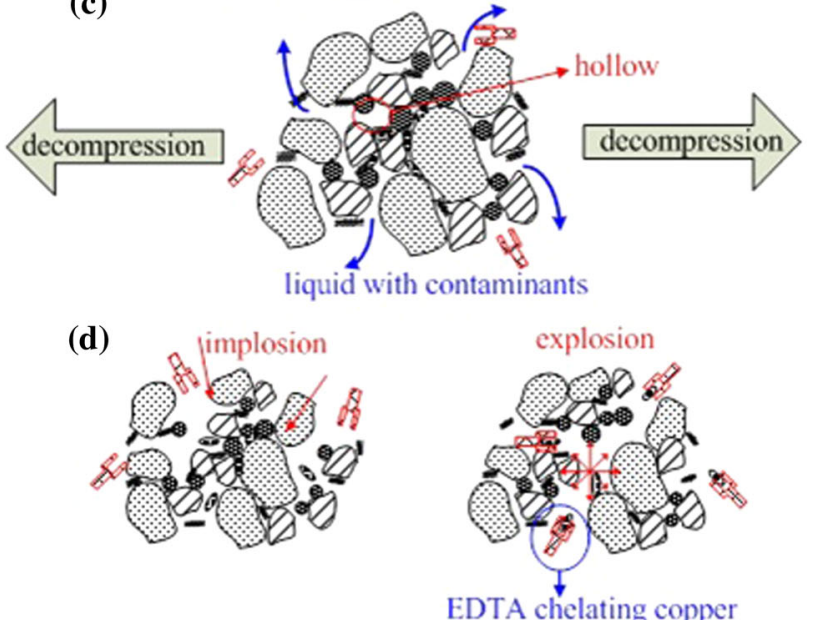

Fig. 6 Mechanisms contributing to increased exposure and extraction of contaminants

containing extract) from soil pores (Fig. 6c). The repeated compression-decompression cycles cause the pore liquid displacement by gas, and sediment pore spaces are then filled with gas. Additional cycles exert pressure on the sediment particles from liquid outside (compression process) or pressure from gas inside sediment pores (decompression process). The sediment pore space of the sediment aggregates is initially filled or partially filled with natural water; increasing pore liquid replacement by air occurs during successive pressure cycles that result in an increasingly hollow sediment aggregate. This hollow sediment aggregate has to resist great pressure exerted on it as long as the water or extraction solvent cannot be transported through the pore space fast enough to equilibrate against the pressure differential during rapid compression or decompression.

Furthermore, when the pressure tolerance of the wall is exceeded, the implosion or explosion of the sediment 
aggregate occurs, which causes the formation of fissure, fractures, and eventual breakage of the aggregate (Fig. 6d). This also causes the increased exposure of the contaminants to chelating agent in the water phase. The main mechanisms of this increased exposure process include flushing, implosion, and explosion via successive pressurized air cycles. The proposed mechanisms of exposure and particle fracturing are verified by particle size distribution analysis following pressure-assisted cyclic washing treatment (Fig. 2). Fracturing of sediment aggregates via pressure cycles provides an effective alternative to grinding before extraction and vigorous agitation during extraction. Although EDTA was used in this study, it is expected that this pressure-assisted technique could be also applied to other chelating agents with varied degrees of improvement while the advantage of this technique (increased contaminant exposure to chelating agent) remains.

\section{Conclusion}

In this study, an innovative sediment remediation system has been developed. This system involves rapid and successive cycles of compression and decompression of nitrogen gas into the liquid phase for heightened chelating extraction of contaminant metals from contaminated sediments. The main concept was to increase the contact frequency between contaminants and chelating agents within the sediment structures. The contaminant removal rate could be enhanced due to the increased efficiency and effectiveness of the reaction.

Results indicate that the operation factors central to extraction effectiveness were pressure, chelant concentration, and extraction time. The extraction effectiveness increased with increased pressure, extraction time, and EDTA concentration. Furthermore, the effectiveness of $\mathrm{Cu}$ removal was greatly improved by repeated washings with fresh chelant batches even when a lower chelant concentration was used. Thus, this is more environmentally and economically advantageous to the sediment extraction.

Sediment particles became smaller after treatment with pressure cycles. This would cause the increased exposure of contaminants to applied chelating agent. Significant removal of $\mathrm{Cu}$ from contaminated sediments was achievable in much shorter reaction time compared to conventional extraction. Thus, this developed process has a potential to be developed into an effective measure without using the conventional mechanical mixing. The pressureassisted process was demonstrated with EDTA, and it could be also implemented for other chelating agents. Thus, the advantages of the pressure cycle system included the following: reduced reaction time, more thorough extraction, and reduced use of the chelating agent.
The pressure-assisted cyclic washing plays a key role in improving the effectiveness of using EDTA on $\mathrm{Cu}$ extraction from sediments. The presence of multiple contaminants in sediments would cause the insufficient extraction efficiency when single extraction agent was applied. Therefore, the pressure cyclic system with multiple washing stages using different extraction agents can be considered for practical application. Furthermore, ambient air can be applied to substitute the nitrogen gas to lower the operational cost. However, the cost for sediment loading, system maintenance/cleaning, and energy costs need to be considered in a scale-up reactor.

It is expected that this pressure-assisted technique could be applied to other reagents (or chemicals) with varied degrees of improvement while the advantage of this technique remains. Results from this study indicate that the developed system is a promising technology to remediate contaminated sediments, and the results will be helpful in designing a scaled-up system for practical applications.

Acknowledgments This project was funded in part by Taiwan National Science Council (Grant No. NSC99-2221-E-110-027-MY3). Additional thanks are extended to the personnel at China Steel Co., Taiwan and Kaohsiung Environmental Protection Bureau, Kaohsiung, Taiwan for their assistance and support throughout this project.

\section{References}

Abumaizar RJ, Smith EH (1999) Heavy metal contaminants removal by soil washing. J Hazard Mater 70:71-85

Akcay H, Oguz A, Karapire C (2003) Study of heavy metal pollution and speciation in BuyakMenderes and Gediz River sediments. Water Res 37:813-822

Amin B, Ismail A, Arshad A (2009) Anthropogenic impacts on heavy metal concentrations in the coastal sediments of Dumai. Indonesia Environ Monit Assess 148:291-305

Arribere MA, Ribeiro GS, Sanchez RS, Gil MI, Roman RG, Daurade LE, Fajon V, Horvat M, Alcalde R, Kestelman AJ (2002) Heavy metals in the vicinity of a chlor-alkali factory in the upper Negro river ecosystem, Northern Patagonia, Argentina. Sci Total Environ 301:187-203

Barona A, Aranguiz I, Elı'as A (2001) Metal association in soils before and after EDTA extractive decontamination: implications for the effectiveness of further clean-up procedures. Environ Pollut 113:79-85

Bermond A, Ghestem JP (2001) Kinetic study of trace metal EDTAdesorption from contaminated soils, heavy metals release in soils. In: Selim HM, Sparks DL (eds) Lewis Publishers: Boca Raton, pp 131-147

Bhakta JN, Munekage Y, Ohnishi K, Jana BB (2012) Isolation and identification of cadmium- and lead-resistant lactic acid bacteria for application as metal removing probiotic. Int J Sci Technol 9:433-440

Casas JM, Rosas H, Solé M, Lao C (2003) Heavy metals and metalloids in sediments from the Llobregat basin. Spain Environ Geol 44:325-332

Cassidy DP, Irvine RL (1998) Interactions between organic contaminants and soil affecting bioavailability, bioremediation-principles and practices. Technomics Lancaster, Pennsylvania, pp 259-282 
Catherine NM, Yong RN, Gibbs BF (2001) An evaluation of technologies for the heavy metal remediation of dredged sediments. J Hazard Mater 85:145-163

Chen ZY, Saito Y, Kanai Y, Wei TY, Li LQ, Yao HS (2004) Low concentration of heavy metals in the Yangtze estuarine sediments, China: a diluting setting Estuarine. Coast Shelf Sci 60:91-100

Chen CF, Chen CW, Dong CD, Kao CM (2012a) Assessment of toxicity of polycyclic aromatic hydrocarbons in sediments of Kaohsiung Harbor, Taiwan. Sci Total Environ in press (available on line)

Chen CT, Chen CW, Chen CF, Dong CD, Ko MS, Kao CM (2012b) Evaluation of zinc contamination in the sediments of Salt River mouth Taiwan. Appl Mech Mater 178-181:893-896

Chiu YM, Huang CH, Chang FC, Kang HY, Wang HP (2011) Recovery of copper from a wastewater for preparation of $\mathrm{Cu}$ nanoparticles sustain. Environ Res 21:279-282

Demirak A, Yilmaz F, Tuna AL, Ozdemir N (2006) Heavy metals in water, sediment and tissues of Leuciscus cephalus from a stream in southwestern Turkey. Chemosphere 63:1451-1458

ECB, European Chemical Bureau (2004) European union risk assessment report on $\mathrm{Na}_{4}$ EDTA, Office for Official Publications of the European Communities, Italy

Elliott HA, Shastri L (1999) Extractive decontamination of metalpolluted soils using oxalate. Water Air Soil Pollut 110:335-346

Fischer K, Bipp HP, Riemschneider P, Leidmann P, Bieniek D, Kettrup A (1998) Utilization of biomass residues for the remediation of metal-polluted soils. Environ Sci Technol 32: 2154-2161

Gao P, Feng YJ, Zhang ZH, Liu JF, Ren NQ (2012) Effect of heavy metals and surfactants on the adsorption of phenolic compounds on sediment. Int J Sci Technol 9:671-682

Ghrefat H, Yusuf N (2006) Assessing $\mathrm{Mn}, \mathrm{Fe}, \mathrm{Cu}, \mathrm{Zn}$, and $\mathrm{Cd}$ pollution in bottom sediments of Wadi Al-Arab Dam, Jordan. Chemosphere 65:2114-2121

Gundersen P, Steinnes E (2003) Influence of $\mathrm{pH}$ and TOC concentration on $\mathrm{Cu}, \mathrm{Zn}, \mathrm{Cd}$, and $\mathrm{Al}$ speciation in rivers. Water Res 37:307-318

Gustavon K, Burton GA, Francingues NR, Reible D, Vorhees DJ, Wolfe JR (2008) Evaluating the effectiveness of contaminatedsediment dredging. Environ Sci Technol 42:5042-5047

Harikumar PS, Nasir UP (2010) Ecotoxicological impact assessment of heavy metal in core sediments of a tropical estuary. Ecotoxicol Environ Saf 73:1742-1747

Hong PAK, Li C, Banerji SK, Regmi T (1999) Extraction, recovery, and biostability of EDTA for remediation of heavy metal contaminated soil. J Soil Contam 8:81-103

Hong PAK, Cai X, Cha Z (2008) Pressure-assisted chelation extraction of lead from contaminated soil. Environ Pollut 153:14-21

Jayawardana DT, Ishiga H, Pitawala HMTGA (2012) Geochemistry of surface sediments in tsunami-affected Sri Lankan lagoons regarding environmental implications. Int J Environ Sci Technol 9:41-55

Juang RS, Wang SW (2000) Metal recovery and EDTA recycling from simulated washing effluents of metal-contaminated soils. Water Res 34:3795-3803

Khaled A, Nemr AE, Sikaily AE (2006) An assessment of heavymetal contamination in surface sediments of the Suez Gulf using geoaccumulation indexes and statistical analysis. Chem Ecol 22:239-252

Lee CS (2003) Fractionation and extractability of copper, zinc, and lead in contaminated soils, Ph.D. dissertation, National Cheng Kung University, Taiwan

Liaghati T, Preda M, Cox M (2003) Heavy metal distribution and controlling factors within coastal plain sediments, bells creek catchment, southeast Queensland Australia. Environ Int 29:935-948

Liang JR, Huang SC (2012) Kinetic model for sulfate/hydroxyl radical oxidation of methylene blue in a thermally-activated persulfate system at various $\mathrm{pH}$ and temperatures sustain. Environ Res 22:199-208

Lim TT, Tay JH, Wang JY (2004) Chelating-agent-enhanced heavy metal extraction from a contaminated acidic soil. J Environ Eng 130:59-66

Lin CE, Chen CT, Kao CM, Hong A, Wu CY (2011) Development of the sediment and water quality management strategies for the Salt-water River Taiwan. Marine Pollut Bull 63:528-534

Liu JY, Cheng SF (2007) Effect of soil particle fractionation on removal efficiency of heavy metals in soils. Department of environmental engineering and management Chaoyang University of Technology, MS Thesis

Martinez CE (2000) Solubility of lead, zinc and copper added to mineral soils. Environ Pollut 107:153-158

Moreda-Pineiro J, Alonso-Rodriguez E, Lopez-Barrerra P (2006) As, $\mathrm{Cd}, \mathrm{Cr}, \mathrm{Ni}$ and $\mathrm{Pb}$ pressurized liquid extraction with acetic acid from marine sediment and soil samples. Spectrochim Acta Part B At Spectrosc 61:1304-1309

Mwamburi J (2003) Variations in trace elements in bottom sediments of major rivers in Lake Victoria's basin, Kenya. Lakes Reserv Res Manag 8:5-13

NIEA (2003) Method of soil quality extraction of heavy metals, NIEA S321.63B

NIEA (2005) Method of soil pH analysis, NIEA S410.61C

Palma LD, Mecozzi R (2007) Heavy metal mobilization from harbor sediments using EDTA and citric acid as chelating agents. J Hazard Mater 147:768-775

Peng JF, Song YH, Yuan P, Cui XY, Qiu GL (2009) The remediation of heavy metals contaminated sediment. J Hazard Mater 161:633-640

Polettini A, Pomi R, Calcagnoli G (2009) Assisted washing for heavy metal and metalloid removal from contaminated dredged materials. Water Air Soil Pollut 196:183-198

Reed BE, Carriere PC, Moore R (1996) Flushing of a Pb(II) contaminated soil using $\mathrm{HCl}$, EDTA and $\mathrm{CaCl}_{2}$. J Environ Eng 122:48-50

Reimann C, de Caritat P (2005) Distinguishing between natural and anthropogenic sources for elements in the environment: regional geochemical surveys versus enrichment factors. Sci Total Environ 337:91-107

Shiue A, Ma CM, Ruan RT, Chang CT (2012) Adsorption kinetics and isotherms for the removal methyl orange from wastewaters using copper oxide catalyst prepared by the waste printed circuit boards sustain. Environ Res 22:209-215

Singh KP, Mohan D, Singh VK, Malik A (2005) Studies on distribution and fractionation of heavy metals in Gomti river sediments-a tributary of the Ganges. J Hydrol 312:14-27

Susana OR, Daniel DLR, Lazaro L, David WG, Katia DA, Jorge B, Francisco M (2005) Assessment of heavy metal levels in Almendares River sediments-Havana city Cuba. Water Res 39:3945-3953

Tandy S, Bossart K, Mueller R, Ritschel J, Hauser L, Schulin R, Nowack B (2004) Extraction of heavy metals from soils using biodegradable chelating agents. Environ Sci Technol 38:937-944

TEPA, Taiwan Environmental Protection Administration (2012) Taiwan soil and groundwater remediation act web, http://sgw.epa.gov.tw/public/En/Default.aspx

Theofanis ZU, Astrid S, Lidia G, Calmano WG (2001) Contaminants in sediments: remobilisation and demobilization. Sci Total Environ 266:195-202

Tsai TT, Kao CM, Surampalli RY, Liang SH (2009) Treatment of fuel-oil contaminated soils by biodegradable surfactant washing 
followed by Fenton-like oxidation. J Environ Eng 135:1015-1024

Uta K, Jens W (2006) Long-term effects of the Aznalcóllar mine spill-heavy metal content and mobility in soils and sediments of the Guadiamar River valley (SW Spain). Sci Total Environ 367:855-871

Voglar D, Lestan D (2010) Electrochemical separation and reuse of EDTA after extraction of $\mathrm{Cu}$ contaminated soil. J Hazard Mater 180:152-157

Wanekaya AK, Myung S, Sadik QA (2002) Pressure assisted chelating extraction: a novel technique for digesting metals in solid matrices. Analyst 127:1272-1276

Wasay SA, Barrington SF, Tokunaga S (2001) Organic acids for the in situ remediation of soils polluted by metals: soil flushing in columns. Water Air Soil Pollut 127:301-314
Xia W, Gao H, Wang X, Zhou C, Liu Y, Fam T, Wang X (2009) Application of EDTA decontamination on soil affected by mining activities and impact of treatment on the geochemical partition of metal contaminants. J Hazard Mater 163:936-940

Yang Y, He Z, Lin Y, Phlips E, Stoffella PJ, Powell CA (2009) Temporal and spatial variations of copper, cadmium, lead, and zinc in Ten Mile Creek in South Florida USA. Water Environ Res 81:40-50

Zhang WH, Lo IMC (2006) EDTA-enhanced washing for remediation of $\mathrm{Pb}$ and/or Zn-contaminated soils. J Environ Eng 132:12821288

Zou Z, Qiu R, Zhang W, Dong H, Zhao Z, Zhang T, Wei X, Cai X (2009) The study of operating variables in soil washing with EDTA. Environ Pollut 157:229-236 